\title{
REUNIÃO REGIONAL DE ACOMPANHAMENTO DA CONFERÊNCIA MUNDIAL SOBRE EDUCAÇÃO SUPERIOR PARA A AMÉRICA LATINA E CARIBE
}

Prof. ${ }^{\text {a Dra }}$ - Maria Amélia Sabbag ZAINKO

Nesta seção estaremos compartilhando informações importantes para a compreensão e o debate técnico-político sobre o ensino superior.

Iniciamos com o relato sobre a Reunião regional de acompanhamento dos resultados da Conferência Mundial de Educação Superior na América Latina e Caribe.

Nos dias 15 e 16 de março de 2001, realizou-se em La Plata - Argentina, a reunião regional de acompanhamento da Conferência Mundial de Educação Superior,organizada pelo Comitê Regional para América Latina e Caribe.

No programa painéis, oficinas e atividades de intercâmbio entre dirigentes da UNESCO, de organismos de pesquisa, de universidades, de organizações não-governamentais.

Como representante do Brasil no Comitê Regional, designado por ocasião da Conferência Mundial, participei do painel Difusão e impacto das Conferências Regional e Mundial. Período 1996-2000, apresentando as seguintes contribuições aos debates.

Gostaria de situar o meu olhar nesse período de 1996 a 2000, quando aconteceram os movimentos de preparação da grande discussão, as conferências regionais, o movimento da Conferência Mundial com sua Declaração sobre a Educação Superior no século XXI: visão e ação e o movimento de difusão dos resultados, objetivando subsidiar as reflexões sobre o futuro da Universidade.

No momento das discussões nas Conferências regionais eu me encontrava participando da administração de uma universidade pública e estatal, muito preocupada com a maneira sorrateira e insinuosa com os fundamentos de um modelo neoliberal de desenvolvimento, adentrava a Universidade sem que a comunidade acadêmica, mesmo a mais combativa se apercebesse de que o neoliberalismo com suas palavras mágicas, produtividade,

* Professora/Pesquisadora do Programa de Pós-Graduação em Educação da PUCPR 
eficácia e eficiência, deitava suas raízes, fazendo com que os dirigentes muito combativos colocassem em prática as determinações do Banco Mundial.

A necessidade de buscar fundamentos para a modificação da prática universitária vigente levou-me, no período, a desenvolver uma tese de doutorado, mostrando como as questões de racionalização de recursos, principalmente os financeiros, por natureza escassos, levava a adoção do planejamento estratégico, como um instrumento de gerência da instituição universitária e aí parte do seu compromisso ficava limitado ao encaminhamento de reformas e não de mudanças estruturais de organização que préestabelecesse o novo como base da construção de uma outra cultura universitária. Mais ainda, propus para a universidade um movimento de construção de uma nova universidade, na qual a educação como formação e como condição de evolução humana se colocava no centro da universidade, buscando uma nova postura do sujeito, recusando a cisão entre as ciências e as humanidades e, mais que isso, entre as ciências da natureza e a cultura, como queria Edgar Morin, em La tête bien faite, para quem é preciso repensar a reforma e reformar o pensamento.

Na universidade pública estatal não me foi possível encaminhar tal movimento e aí a Conferência Mundial de Educação Superior acontece quando, presidindo uma organização não-governamental, preocupada com essa concepção, sou chamada para colocar em prática essa nova proposta de Educação em uma universidade de caráter privado.

A difusão dos resultados da Conferência Mundial foram então por mim acompanhados a partir da prática de trabalho em uma instituição particular comunitária (como aliás um número significativo de professores universitários que vêm sendo expurgados do serviço público federal).

Situada a ótica das considerações que trago ao debate, algumas questões têm se colocado como fundamentais para o entendimento do que representou e tem representado esse esforço de mobilização.

O inegável papel de sustentáculo da resistência que a UNESCO tem desempenhado subsidiando a reflexão, apontando caminhos, financiando propostas.

A base de sustentação da política educacional no Brasil e nos países da América Latina e Caribe centrada nas orientações do Banco Mundial o que condiciona e determina as mudanças que se fazem necessárias na Educação Superior.

Por outro lado, considerando que a Declaração se constituiu em documento baseado em referencial crítico-cultural e, portanto, poderia e deveria ser considerado como voz de resistência à exclusão, de promoção da inclusão, do entendimento intercultural, do reforço dos laços entre Universidade e Sociedade; de uma nova visão da Educação Superior calcada na consciência do seu papel para o desenvolvimento sócio-cultural e econômico.

Ora isto implica em uma revisão do processo de formação vigente. 
Para educar, formar e realizar pesquisas, missões básicas estabelecidas no documento associando às funções ética, autonomia, responsabilidade e prospectiva, é preciso construir movimento de revisão da prática universitária.

Não foi isso que se verificou no Brasil onde a grande difusão se deu pela publicação dos documentos da Conferência e pela sua distribuição aos interessados.

O grande debate, a seqüência do movimento de reflexão, encontrou as universidades públicas mais uma vez envoltas em seus crônicos problemas financeiros e as autoridades educacionais brasileiras preocupadas com a fixação de padrões de formação que possibilitassem o exame único.

Assim, nem mesmo os seminários realizados para discutir as propostas de novas Diretrizes Curriculares representaram uma perspectiva de revisão efetiva do processo de formação que se dá na Educação Superior.

As discussões comprometidas com uma renovação da prática pedagógica ocorreram então em algumas instituições particulares,que por não terem o destaque das públicas, acabaram restringindo o impacto das propostas, muitas vezes inovadoras na sua concepção, mas tradicionais na sua aplicação.

Nesse período,quase que por ironia, já que a recomendação da Conferência Mundial enfatizava a necessidade de democratização do acesso, ocorre uma expansão desenfreada do Ensino Superior Privado, promovendo uma democratização as avessas, uma vez que a condição do acesso está determinada pela possibilidade de fazer frente aos altos custos de financiamento dos estudos superiores.

Ainda, no que tange à revisão das formas de acesso, as discussões não avançam. É mantido o exame vestibular, que mais do que selecionar por mérito, promove a seletividade social, não há expansão significativa de vagas, a não ser nas instituições particulares, que não conseguem preenchê-las e introduz-se o exame nacional do ensino médio, também um exame padrão único, como forma de aproximação entre os graus de ensino.

As Diretrizes curriculares passam a representar o grande esforço de revisão do processo de formação. Porém, sem uma visão integrada e integradora do processo de formação, representam apenas novas propostas fragmentadas, portanto sem obedecer os requisitos da pertinência, da qualidade e da globalidade.

Neste processo, a pesquisa continua individual e sem relevância social, o intercâmbio, a cooperação e o reforço dos laços com a sociedade ainda permanecem no campo do desejável, mas não necessariamente exeqüível.

A grande questão que a todos desafia é determinada pela incorporação da visão gerencial para a qual é necessário melhorar a gestão, contando com dirigentes que sejam bons administradores, administradores modernos. Aqui cabe lembrar o alerta de Cristovam Buarque em A Aventura da Universidade, para quem "as instituições devem ter como dirigentes líderes intelec- 
tuais, pois bons gerentes podem conduzir organizadamente a universidade para a mesmice".

Produtividade,eficiência e eficácia, tal qual na visão empresarial, são os parâmetros de qualidade numa ótica gerencial e econômica, que enfatiza sobremaneira os aspectos quantitativos, burocratizando e inviabilizando as perspectivas de uma avaliação institucional que efetivamente ofereça transparência e aproximação com a sociedade. Também na perspectiva de parâmetros e padrões fixos de rendimento, o exame nacional de cursos - provão, como exame único, é o principal indicador de qualidade dos processos de formação.

A autonomia sem articular de maneira adequada a participação e representação (condições indispensáveis para a legitimidade ) continua a ser a questão que permanece no centro dos debates, ainda que de forma inviesada, de vez que se concentra primordialmente nos aspectos financeiros.

Como vêem não é muito animadora a forma como no Brasil estamos encaminhando as propostas e recomendações da Conferência Mundial de Educação Superior.

No painel Educação superior nos países em desenvolvimento: perigos e promessas, os painelistas Luis Yarzabal, Presidente do ILAEDES e ex- Diretor do IESALC/UNESCO e Hélgio Trindade, ex- Reitor da UFRGS e atual coordenador do CIPEDES, apresentaram de forma bastante crítica as suas percepções sobre o documento produzido em conjunto por técnicos da UNESCO e do BANCO MUNDIAL

O documento que procura responder questões relacionadas com a idéia de que é necessário produzir educação da melhor qualidade e torná-la disponível para todos foi elaborado por uma força-tarefa (TASK FORCE) constituída por 14 "experts" de 13 países, sendo 8 dirigentes universitários, 4 dirigentes de organizações estatais e 2 professores universitários.

Trabalhando durante 8 meses, apoiado por 9 investigadores e contando com a contribuição de 93 países, o grupo de especialistas realizou 6 seminários, intercâmbios, estudos de caso.

Com uma forte presença dos Estados Unidos, o documento contou para sua elaboração com a contribuição dos especialistas brasileiros: José Goldemberg, como representante do Brasil, Cláudio de Moura Castro e Simon Schwartzman, como estudiosos da questão vinculados ao Banco Mundial. A redação final ficou sob a responsabilidade de David Bloom e Henry Rosovsky, ambos da Universidade de Harvard, garantindo, assim, a supremacia da visão norte-americana.

Muito embora analisando alguns temas que têm sido objeto de estudos por parte da UNESCO, o documento se assemelha muito mais aos documentos do Banco Mundial, principalmente no que tange a sua metodologia de elaboração, que ignora o movimento de discussões e de enfrentamento conjunto dos problemas, marca registrada da UNESCO. 
Neste sentido, valendo-se da posição do Banco Mundial, que reconhece que o Consenso de Washington é um fracasso, o documento que não se sustenta em termos de lógica argumentativa, superdimensiona o papel e o poder da educação como causa e solução da pobreza, provocando uma impressão, compartilhada por muitos estudiosos, de que o documento teria sido elaborado intencionalmente contra o movimento de mobilização que culminou com a Conferência Mundial de Educação Superior, realizada em Paris de 5 a 8 de outubro de 1998 .

Dentre os vários aspectos abordados, o documento defende a revalorização da Educação Superior e da investigação voltada para o desenvolvimento econômico; o sistema estratificado de ensino superior composto por universidades de pesquisa, universidades estaduais e/ou regionais, faculdades profissionais e escolas/faculdades vocacionais, com líderes fortes. Ao apontar a má-administração como o principal problema do ensino superior, há o conhecido reforço à idéia de que a lógica empresarial deve presidir as discussões, também no campo educacional.

Neste sentido, a autonomia fica restrita ao seu aspecto de gestão financeira, mais especificamente no que tange à captação de recursos.

No seu todo, o documento deixa transparecer um sutil enfoque de mercado e uma forte discriminação em relação aos países em desenvolvimento, atribuindo-lhes um papel de subordinação, uma vez que deveriam ser guiados por especialistas internacionais.

Por fim, ao negar pontos fundamentais contidos nos documentos de política de ensino superior da UNESCO, como a perspectiva educacional mais voltada para os seres humanos e meio-ambiente e não para o mercado, parece mesmo que o documento "conjunto" respondeu a interesses políticos e utilizou a UNESCO como fornecedora de dados estatísticos.

Uma visão mais aprofundada, a partir de uma análise crítica bastante circunstanciada, pode ser obtida com a consulta ao texto da Prof ${ }^{\mathrm{a}}$ Angela C. de Siqueira, da Faculdade de Educação da Universidade Federal Fluminense, publicado na Revista Avaliação da RAIES, volume 6, nº 1(19)- março de 2001.

La Plata, 17 de março de 2001.

e-mail: maszainko@civitas.org.br 